\title{
Effective Method to Resolve the Chromosome Numbers in Pistacia Species (Anacardiaceae)
}

\author{
Mohannad Al-Saghir ${ }^{1 *}$, Shadi Abu Baker ${ }^{2}$, Robert Pusok ${ }^{1}$ \\ ${ }^{1}$ Department of Environmental and Plant Biology, Ohio University Zanesville, Zanesville, $\mathrm{OH}, \mathrm{USA}$ \\ ${ }^{2}$ Department of Chemistry, Ohio University Zanesville, Zanesville, $\mathrm{OH}, \mathrm{USA}$ \\ Email: ${ }^{*}$ al-saghi@ohio.edu
}

Received 13 July 2014; revised 15 August 2014; accepted 27 August 2014

Copyright (C) 2014 by authors and Scientific Research Publishing Inc.

This work is licensed under the Creative Commons Attribution International License (CC BY).

http://creativecommons.org/licenses/by/4.0/

(c) (i) Open Access

\begin{abstract}
The genus Pistacia L. belongs to the Anacardiaceae family and includes at least eleven species. Cytogenetic studies addressing the genus Pistacia are rather few. Chromosome numbers of the different Pistacia species, revealed by these studies, are questionable due to the fact that poor chromosome counting protocols were used, and these protocols are hampered by the extremely smallsized chromosomes of Pistacia species. The aim of this study was to develop a more effective method to resolve the chromosome numbers in Pistacia species using a fluorescent microscope. The method described here is modified from the Sigma Plant Protoplast Digest/Wash Solution protocol. The method used here is highly effective for karyotyping analysis and studying population genetics of Pistacia species. Moreover, it is easy and can be reproduced for other species that have smaller chromosomes. This method can be used for plant herbarium specimens or field plants. This study provides valuable chromosomal data for cytogeneticists and plant breeders who are working on this genus. It provides additional insight into understanding the taxonomic and phylogenetic relationships among Pistacia species. The chromosomes described here are also suitable for gene and genome mapping.
\end{abstract}

\section{Keywords}

Pistacia, Cytogenetics, Chromosome Numbers, Fluorescent Microscopy

\footnotetext{
*Corresponding author.
}

How to cite this paper: Al-Saghir, M., Abu Baker, S. and Pusok, R. (2014) Effective Method to Resolve the Chromosome Numbers in Pistacia Species (Anacardiaceae). American Journal of Plant Sciences, 5, 2913-2916. 


\section{Introduction}

The genus Pistacia L. belongs to the Anacardiaceae family and includes at least eleven species [1]. The genus includes Pistacia vera L., the cultured pistachio, which has edible nuts and considerable commercial importance [1]. The other species grow in the wild and their seeds are used as a rootstock seed source and sometimes are used for fruit consumption, oil extraction, or soap production [1].

The pistachio is native to the arid zones of Central Asia; it has been cultivated for 3000 - 4000 years in Iran and was introduced into Mediterranean Europe by Romans at the beginning of the Christian Era [2]. Pistachio cultivation extended westward from its center of origin to Italy, Spain, and other Mediterranean regions of Southern Europe, North Africa, and the Middle East, as well as to China, and more recently to the United States and Australia [3]. Pistachios are adapted to a variety of soils and are probably more tolerant of alkaline and saline soil than most tree crops [4].

Chromosomal data have been valuable resource for cytogeneticists and plant breeders. They often provide more insight into taxonomic and phylogenetic relationships [5] [6].

Cytogenetic studies addressing the genus Pistacia are rather few. Previous studies showed that all Pistacia species are diploid with chromosome numbers $2 n=24,28$, and $30.2 n=28$ was reported for $P$. atlantica or its subspecies by several researchers [7]-[9]. However, a recent study by Ila et al. [10] reported the chromosome number for the first time as $2 \mathrm{n}=30$ for the same species.

Chromosome number of $P$. chinensis was reported as $2 n=24$ [11] [12]. Chromosome number of $P$. eurycarpa was reported as $2 \mathrm{n}=30$ [10] for the first time. Chromosome number of $P$. intergimma was reported as $2 \mathrm{n}=$ 30 [13]-[16]. Chromosome number of $P$. khinjuk was reported as $2 n=24$ [9] and as $2 n=30$ [8]. $2 n=24$ was reported for $P$. lentiscus [7] [9] [17] and $2 \mathrm{n}=30$ [18]. Chromosome number for $P$. terebinthus was reported as $2 \mathrm{n}=30$ [8] [10] [17]. Chromosome number for $P$. vera was $2 \mathrm{n}=30$ [7] [8] [19]-[21].

Chromosome numbers of the different Pistacia species are questionable and controversial due to the fact that poor chromosome counting protocols were used [10]; these protocols are hampered by the extremely small-sized chromosomes of Pistacia species and a few cell divisions were visible in a single root tip [21].

The aim of this study was to develop a more effective method to resolve the chromosome numbers in Pistacia species using a fluorescent microscope and provide more insight into understanding the cytogenetics and phylogeny of the genus Pistacia. The method described here is modified from the Sigma Plant Protoplast Digest/ Wash Solution protocol (Sigma, St. Louis, MO, USA).

\section{Materials and Methods}

\subsection{Plant Materials}

Leaves from the herbarium specimens of Pistacia atlantica Desf., $P$. khinjuk Stocks., P. lentiscus L. and $P$. terebinthus L. were used. The specimens were obtained from the Massey Herbarium, Department of Biological Sciences, Virginia Polytechnic Institute and State University Tech, Blacksburg, Virginia. All plants were collected by the first author in Jordan in 2004.

\subsection{Chromosome Preparation}

In this study, the Sigma Plant Protoplast Digest/Wash Solution protocol (Sigma, St. Louis, MO, USA) was modified and can be reproduced specifically for Pistacia species as the following:

$1 \mathrm{~g}$ of leaf tissue was gathered from each specimen and sliced into $1 \mathrm{~mm}$ strips with a sharp blade. The tissue strips were placed in $50 \mathrm{~mL}$ conical vials, each filled with $20 \mathrm{~mL}$ of Plant Protoplast Digest/Wash Solution (Sigma, St. Louis, MO, USA). After being mixed via inversion for $5 \mathrm{~min}$, the Digest/Wash Solution was removed leaving only the leaf tissue. To the leaf tissue $10 \mathrm{~mL}$ of the digestion enzyme solution was added and mixed via inversion for $2 \mathrm{~min}$. The mixture was then gently agitated on the platform shaker for one hour.

After $1 \mathrm{~h}, 50 \mu \mathrm{L}$ of each mixture was diluted into 4 micro centrifuge tubes each containing $450 \mu \mathrm{L}$ of Digest/Wash Solution. The mixtures were spun at $100 \times$ g-forces for 5 min; the supernatant was removed leaving the pellets intact.

$20 \mathrm{~mL}$ of Digest/Wash Solution was added to the pellets and was mixed via inversion. The mixture was spun again at $100 \times$ g-forces for $5 \mathrm{~min}$. The supernatant was then removed and $10 \mu \mathrm{L}$ of fixative was added to each pellet, the pellets were then re-suspended via inversion and chilled on ice for one hour. The chilled mixtures 


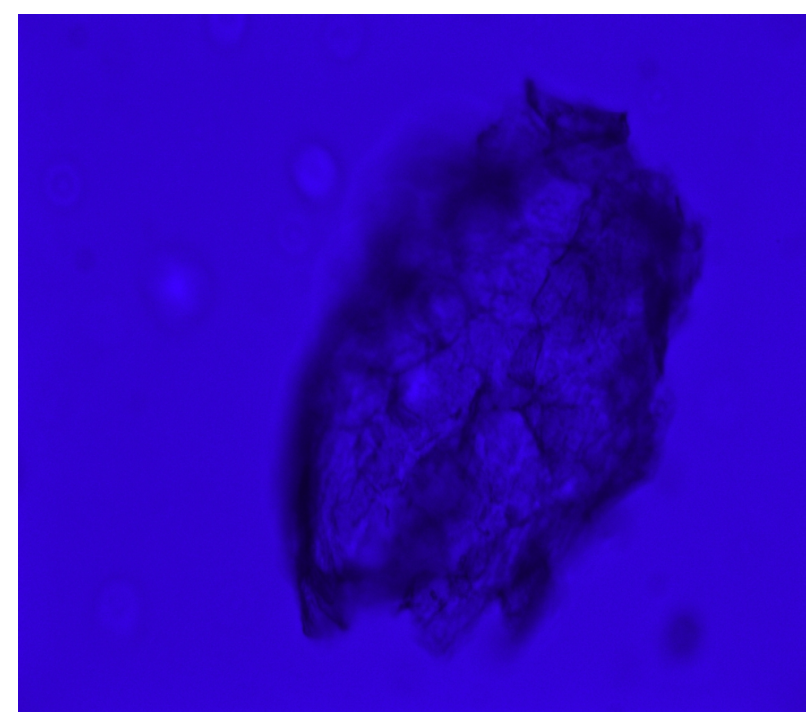

Figure 1. Cell with chromosomes $(2 \mathrm{n}=30)$ of Pistacia atlan tica Desf.

were dropped onto room-temperature slides. The slides were stained with 4'-6-diamidino-2-phenylindole (DAPI) (Sigma, St. Louis, MO, USA) and placed under fluorescent microscope (Leica, Wetzlar, Germany).

\section{Results and Discussion}

The results show that all used Pistacia species are diploid and they have the same chromosome number of $2 \mathrm{n}=$ 30 (Figure 1).

This study is the first to report the chromosome numbers using fluorescent microscope. The method was developed for Pistacia species because root-tips from the field are not possible to obtain and roots from seedlings are far too small. Moreover, the Pistacia species have very small chromosomes.

The method used here is highly effective for karyotyping analysis and studying population genetics of Pistacia species. Moreover, it is easy and can be reproduced for other species that have smaller chromosomes. This method can be used for plant herbarium or field plants.

This study provides valuable chromosomal data for cytogeneticists and plant breeders who are working on this genus. It provides additional insight into understanding the taxonomic and phylogenetic relationships among Pistacia species. The chromosomes described here are also suitable for gene and genome mapping.

\section{Acknowledgements}

The authors are grateful to Ohio University Zanesville for funding this project.

\section{References}

[1] Al-Saghir, M.G. (2010) Phylogenetic Analysis of the Genus Pistacia L. (Anacardiaceae) Based on Morphological Data. Asian Journal of Plant Sciences, 9, 28-35. http://dx.doi.org/10.3923/ajps.2010.28.35

[2] Crane, J.C. (1974) Hermaphroditism in Pistacia. California Agriculture, 28, 3-4.

[3] Maggs, D.H. (1973) Genetic Resources in Pistachio. Plant Genetic Resources Newsletter, 29, 7-15.

[4] Tous, J. and Ferguson, L. (1996) Mediterranean Fruits. In: Janick, J., Ed., Progress in New Crops, ASHS Press, Arlington, 416-430.

[5] Raven, P.H. (1975) The Bases of Angiosperm Phylogeny: Cytology. Annals of the Missouri Botanical Garden, 62, 724-764. http://dx.doi.org/10.2307/2395272

[6] Stuessy, T.F. (1990) Plant Taxonomy. Columbia University Press, New York.

[7] Zohary, M. (1952) A Monographical Study of the Genus Pistacia. Palestine Journal of Botany, Jerusalem Series, 5, 187-228. 
[8] Ozbek, S. and Ayfer, M. (1957) Pistacia turleri uzerinde sitolojik arastirmalar. Ankara Univeristiesi Ziraat Fakultesi Yilligi, 3, 203-222.

[9] Ghaffari, S.M. and Harandi, O.F. (2002) Chromosome Counts and Assessment of Two Heterochromatic Chromosomes in Some Species of Pistacia L. from Iran. Acta Horticulture, 591, 389-393.

[10] Ila, H.B., Kafkas, S. and Topaktas, M. (2003) Chromosome Numbers of Four Pistacia (Anacardiaceae) Species. Journal of Horticulture Science and Biotechnology, 78, 35-38.

[11] Huang, S.F., Chen, Z.Y., Chen, S.J., Huang, X.X., Qi, Q.Y. and Shi, X.H. (1986) Plants Chromosome Count (3). Subtropical Forest Science and Technology, 4, 50-56.

[12] Huang, S.F., Zhao, Z.F., Chen, Z.Y., Chen, S.J. and Huang, X.X. (1989) Chromosome Counts on Hundred Species and Infraspecific Taxa. Acta Botanica Austro Sinica, 5, 161-176.

[13] Mehra, P.N. and Sareen, E.T.S. (1969) In IOPB Chromosome Number Reports XXII. Taxon, 18, 433-442.

[14] Mehra, P.N. (1976) Cytology of Himalayan Hardwoods. Sree Saraswaty Press, Calcutta.

[15] Gill, B.S., Bir, S.S. and Singhal, V.K. (1984) Cytological Studies in Some Western Himalayan Wood Species II. Polypetalae. In: Paliwal, G.S., Ed., The Vegetational Wealth of the Himalayas, Puja Publication, Delhi, 497-515.

[16] Sandhu, P.S. and Mann, S.K. (1988) SOCGI Plant Chromosome Number Reports VII. Journal of Cytology and Genetics, 23, 219-228.

[17] Nilsson, Q. and Lassen, P. (1971) Chromosome Numbers of Vascular Plants from Austria, Mallorca and Yugoslavia. Botaniska Notiser, 124, 270-276.

[18] Natarajan, G. (1978) In IOPB Chromosome Number Reports LXII. Taxon, 27, 519-535.

[19] Bochantseva, Z.P. (1972) Ochislakh Chromosome. Introd. Akkli. Rasteny Akad. Nauk. UZ. SSR, 44-53.

[20] Harandi, O.F. and Ghaffari, M. (2001) Chromosomal Studies on Pistachio (Pistacia vera L.) from Iran. Cahiers Options Méditerranéennes, 56, 35-40.

[21] Ayaz, E. and Namli, S. (2009) The Karyotype Analysis of Pistacia vera L. from Turkey. Natural Product Research, 23, 866-870. http://dx.doi.org/10.1080/14786410802263675 
Scientific Research Publishing (SCIRP) is one of the largest Open Access journal publishers. It is currently publishing more than 200 open access, online, peer-reviewed journals covering a wide range of academic disciplines. SCIRP serves the worldwide academic communities and contributes to the progress and application of science with its publication.

Other selected journals from SCIRP are listed as below. Submit your manuscript to us via either submit@scirp.org or Online Submission Portal.
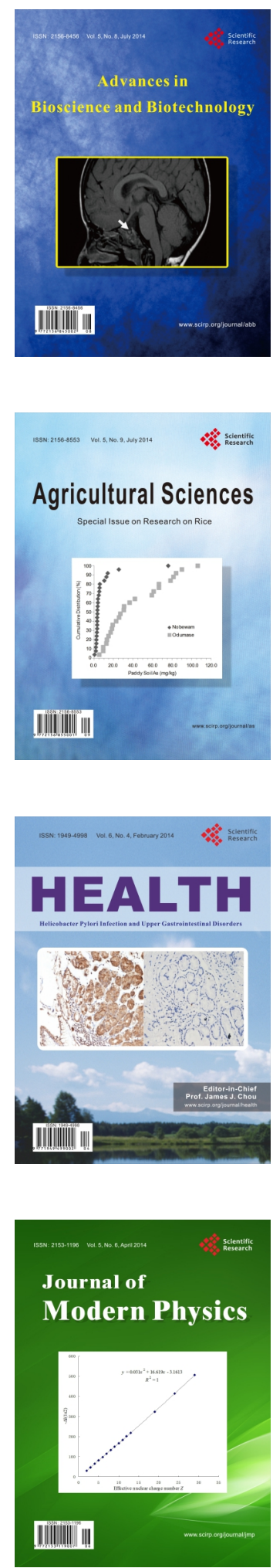
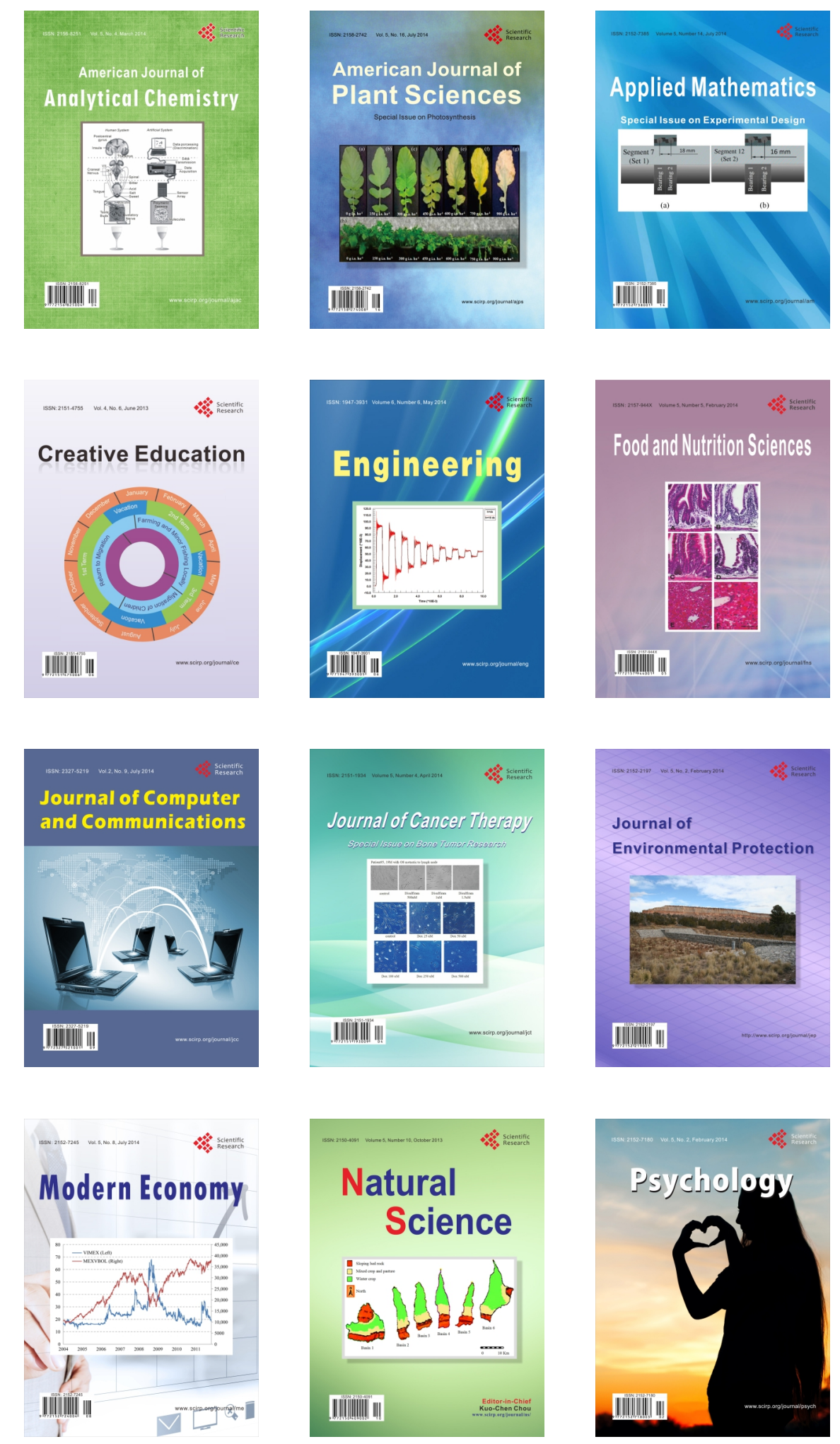